must insist upon asking questions and getting their answers from Nature rather than from a Dr. Goebbels.

Dr. B. Schober (Czechoslovakia) gave details of the destruction of Czechoslovak scientific culture since Nazi occupation, and the persecution of the students and professors following their resistance to fascist domination. The health of the nation is deteriorating rapidly since the food supplies available provide only one- to two-thirds of the essential calories. Mr. P. M. Yap contrasted the scientific spirit in China and Japan, showing that the Japanese treatment of science follows very closely that of Germany. Full scientific progress in China has been retarded in the past by its dependence upon political and social conditions, but at present these are highly favourable and science is receiving the support of both Government and people. Mr. J. J. Ducenne dealt with the general position of science in Belgium before the War, and then gave impressions of the struggle between men of science and the occupying Nazis.

Prof. J. B. S. Haldane paid a tribute to the scientific workers who had been able to escape from occupied countries and were giving us inestimable help in our destruction of fascism. He then dealt with science in the U.S.S.R., stating that the system of planning had enabled the country to mobilize all men of science for the war effort much more quickly than we could. Planning was done largely by men of science in the U.S.S.R., and it was important to realize that the present power of the Red Army was due to scientific planning in the past, particularly in geological research, which employs some two thousand trained geologists. He thought that undoubtedly the Soviet Union had something to learn from Great Britain regarding liberty; similarly we might learn a lot from the Soviets about planning. It was allimportant that we should learn how to combine planning and freedom, for that was the key problem of the future. It must be realized that scientific workers are skilled manual workers, and we must resist any attempt by educationists to make a gap between the two. The utmost scientific knowledge must be given to ordinary people.

Dr. G. Fournier (France) showed that it was impossible for the man of science to live remote from politics and the affairs of the world. Too many men of science had, said : "I am not interested in polities". Now the politicians have become too interested in the men of science, and as a result many had found themselves in custody, and their books burnt. Science has a social value and the man of science cannot wash his hands of his discoveries. It is his duty to see that they are used for the betterment of mankind, and not for its destruction. In future he must be continuously alert to ensure that fascism does not reappear under some other name elsewhere in the world.

Dr. J. G. Siebert (Germany) summed up the discussion, and by resolution the meeting sent its greetings to peoples in subjected countries, and expressed the view that, as rational organization of science for the purpose of waging war would bring victory over the Axis powers, a thorough co-ordination of scientific and technical enterprise could forge weapons to destroy the evils of want, disease, and ignorance which would still have to be confronted when the War was won. The meeting pledged fullest support for "the impending large-scale decisive invasion of the European continent. We call on all scientists and technicians to give of their utmost, whether in workshop or in hospital, in laboratory or at the battlefront".

\section{CIVILIAN CONTRIBUTION TO EDUCATION IN THE FORCES}

HE Report of the Central Advisory Council for
Education in H.M. Forces for the period October
1942-March 1943 again directs attention to the
remarkable way in which the project is growing.
Much of the increase in demand can be explained by
the introduction of compulsory educational periods
in the Army during training hours for the months
November-February. This not only increased the
desire for supplementary lectures by experienced
civilians but has, principally in Anti-Aircraft Com-
mand, called for aid from the university and university
college regional committees in giving the suggested
talks on citizenship in a number of small units which
do not possess suitable teachers within their ranks.
Steps taken by the Royal Air Force, and more recently
by the Royal Navy, to encourage the study of current
affairs, account for an increase in educational activi-
ties by these Services proportionately greater than ties by these Serv
that for the Army.

There has been an increased demand for lectures and classes by many women's units. Efforts have been made to meet this demand by adding lecturers to regional panels who are particularly well equipped to give the personal approach and treatment of subject which is required by audiences of women. At one A.T.S. conference it was revealed that arranging education in women's units is often more difficult than in men's units, but that the A.T.S. could do much more in the way of education if the right subjects and approach could be found. A profitable introduction to citizenship was being made in women's units through their interest in social services.

An interesting development has been the increase in the number of "site visitors". These are men and women who visit small units at regular intervals to guide and advise units on many social and educational matters. Usually the visit takes the form of an informal talk or discussion and is often followed by requests for help or information in regard to all kinds of group or individual activities. The voluntary organizations connected with education have contributed greatly to the success of these site visits.

People who are interested in the development of residential colleges for adult education for the civilian population will find much to interest them in the short schools and conferences which were arranged by the regional committees for H.M. Forces. In the period under review, 126 of these courses, etc., were held, 44 of them being residential. They were attended by 4,398 Service men and women, including members of the U.S. Forces. One of these courses was of three weeks duration and dealt with the basic elements of responsible citizenship, while other courses of the same nature lasted for shorter periods. The experiences gained during these periods of residential study should be of great value to educationists connected with adult work in the post-war period. It should be pointed out that similar courses were arranged for men and women from the Dominions, the fighting services of other members of the United Nations and the merchant navies of Britain and other countries.

The statistics issued in this report show that the number of single lectures given by civilian lecturers. was 61,546 , an increase of 44 per cent over the previous six months. The number of short courses increased 
by 15 per cent to 3,223 , while the number of continuous classes rose to 1,369 , an increase of 35 per cent.

Topics of current interest were responsible for much of the increase, while the increase in non-vocational science and psychology (classified separately) was very considerable. Handicrafts again proved popular and increased in number, but the shortage of materials has hindered the formation of classes in a number of crafts.

The growing volume of work undertaken by the regional committec $\mathrm{s}$ is a tribute not only to all the individuals who take part in the work but also to the Service authorities for their wisdom in encouraging educational activities am ng serving men and women.

\section{PROPOSALS FOR NEW BASIC PHYSICAL POSTULATES}

TN a series of papers published in 1942, some in the 1 Manual of Myiology, Dr. H. T. Townsend, of S. Paulo, Brazil, puts forward a revolutionary set of new physical theories. While there does not appear to be adequate evidence for the views put forward in the papers under notice, the following are principal postulates, mainly in the author's own words :

Centrifugal force is inherent in all cosmogen (mass + motion) and is the most basic cosmic force. Gravity is an equally basic cosmic force. Hence the two are one and the same force. Gravity is the complement of bound centrifugal force. It is unbound centrifugal force. Centrifugal force makes up all cosmogen by its interaction with the actinionic medium. Spinning actinions spinning round a vortex centre are the basis and the electron formed from them spins inherently. Spinning atoms are formed from spinning electrons and spinning molecules from spinning atoms. Centrifugal force centres vary from innumerable microfield centres (vortices in the medium) to the single great cosmic field centre, and each maintains its individual electro-magnetodynamic (commonly called magnetic) field. The repulsions between these fields constitute the force of gravity. Electromagnetic radiation is micro-centrifugal fields in wave formation travelling at top speed in the transmitting (actionic) medium.

The number of atomic weight units in the elec. tronic unit is 546, which thus becomes the basic physical constant. All the atomic weights of the chemical elements are multiples of 546. The actinion carries the force quantum of $12 \times 10^{-30} \mathrm{dyne}$, the equivalent of the motion of 546 actinions constituting a photon. A photon is pure energy acting on the mass of the transmitting actionic medium. The ultimate force quantum is the dynamion, which on coming in contact with an ultimate mass particle or akinesion at once imparts to it an ultimate energy quantum or kinesion, resulting in an actinion. A photon is 546 kinesions, or the result of 546 liberated dynamions imparting 546 motion units to as many actinions.

Applying the 546-multiple key to the light-velocity problem, it is found that the only number within the limited range of Michelson's (1927) experimental results that is a multiple of the square of 546 is 29979737424, which is also within the Henning and Jaeger corrected range of Rosa and Dorsey's (1907) measurements of the electrostatic unit to the electromagnetic unit ratio in our terms of light velocity. It is Michelson's lower to mean record plus the possible retardation by his mirrors.

\section{FORTHCOMING EVENTS}

\author{
Saturday, September II
}

British Federation of Busingss and Professional Women (at the Royal Institution, 21 Albemarle Street, Piccadilly, London, W 1) at 3 p.m.-Dr. Margaret Mead: "Science, Women and the Problem of Power".

\section{Saturday, September 18}

BRITISH RHEOLOGIST'S CLUB (at Loughborough College, Loughborough), at 10 a.m.-Discussion on "Rheology in the Hosiery, Leather, Shoe and Allied Trades".

ASSOCIATION FOR SCIENTIFIC PHOTOGRAPHY (at the Middlesex Hospital, London, W.1), at 2.30 p.m.-Discussion on "Clinical Photography".

Saturday, September 18-Sunday, September 19

Assoctation OF SPECIAL LIBRARIES aND INFORMation BUREAUX (at the Royal Society, Burlington House, Piccadilly, London, W.1).Eighteenth ASLIB Conference.

Saturday, September 18

10.30 a.m.-Annual General Meeting.

11.30 a.m.-.-Prof. J. D. Bernal, F.R.S.: "Positive Information

2.0 p.m.-Symposium on "The International Rehabilitation of Special Library Services".

Sunday, September 19

10.30 a.m.-Mr. F. C. Francis: "The British Museum as a Special Library".

11.45 a.m.-Major Irving Newman : "The Organisation of American Photographic Information Services in Great Britain".

2.30 p.m.- Symposium on "The Co-ordination of Abstracting".

5.0 p.m.- "ASLIB : What it is Doing and What it Hopes to Do",

\section{APPOINTMENTS VACANT}

APPLICATIONS are invited for the following appointments on or before the dates mentioned

assistant Master to teach Engineering DRAwing in the Mid dlesbrough Technical School for Boys-The Director of Education, Education Offices, Middlesbrough (September 18)

HeAD OF THE DEPaRTMENT OF MATHeMatics-The Principal, Heriot Watt College, Edinburgh (September 20).

heads of the Departments of Physiology, Medicine, avi SURGEHY-The Bursar, Royal Veterinary College and Hospital, at The University, Reading (October 1 )

ChaIR of NAval ARchitecture-The Acting Secretary of University Court, The University, Glasgow (October 4).

DIRECTOR OF ROBERT GORDON'S TECHNICAI COLLEGE-The Secre tary, Robert Gordon's 'Technical College, Aberdeen (October 16).

CHIEF CERAMIC RESEARCH CHEMIST-The Ministry of Labour and National Service, Central (Technical and Scientific) Register Labour and House, Kingsway, London, W.C.2 (quoting Reference No. O.N.F. $1457 \mathrm{X})$.

\section{REPORTS and other PUBLICATIONS}

\author{
(not included in the monthly Books Supplement)
}

\section{Great Britain and Ireland}

London School of Hygiene and Tropical Medicine (University of London) incorporating the Ross Institute. Report of a Meeting of the Ross Institute Industrial Advisory Committee on Thursday 27th May 1943. Pp. 24. (London: London School of Hygiene and Tropical Medicine.)
[128 Imperial Agricultural Bureaux. Joint Publication No. 5 : The Production of Seed of Root Crops and Vegetables. Pp. 96. (East Malling: Imperial Bureau of Horticulture and Plantation Crops Aberystwyth: Imperial Bureau of Pastures and Forage Crops Cambridge: Imperial Bureau of Plant Breeding and Genetics.) Institute of Welding. Twentieth Annual Report of the Council, Accounts and Balance Sheet to 31 December 1942. Pp. 20. (London Accounts and Batute of Welding.)
[178 Otto Jespersen : his Work for an International Auxiliary Language. By H. Jacob. Pp. 32. (Loughton: International Language (Ido) Society of Great Britain.) $1 s$.

\section{Other Countries}

Proceedings of the Academy of Natural Sciences of Philadelphia. Vol. 93, 1941. Pp. iii +336. (Philadelphia, Pa. : Academy of Natural Sciences.) 7.50 dollars. $[128$ Fifty-eighth Annual Report of the Bureau of American Ethnology to the Secretary of the Smithsonian Institution, 1940-1941. Pp. 13. (Washington, D.C. : Government Printing Office.) [128 Smithsonian Institution: Bureau of American Ethnology. Bulletin 129: An Archaeological Survey of Pickwick Basin in the adjacent portions of the States of Alabama, Mississippi and Tennessee. By William S. Webb and David $\mathbf{L}$. DeJarnette; with Additions by Walcer B. Jones, J. P. E. Morrison, Marshall T. Newman and Charles E. Snow and William G. Haag. Pp. xxii $+536+316$ plates. (Washington, 